ERRATA CORRIGE

\title{
Two Extensions of the Alternating Algorithm of Von Neumann (*).
}

\author{
Ann. Mat. Pura e Appl., (IV), CXXXIV, pp. 79-91
}

0. Franchetti (Firenze) - S. M. Holland (Lancaster)

In Theorem 1 and Theorem 2 the assumption that $U+V$ is a linear subspace cannot be omitted. In fact, the given proof relies on the fact that $J_{2 n}\left(w-w_{n}\right) \leqslant \sigma_{n}$ $\left(\sigma_{n} \rightarrow 0\right)$ which does not follow from the established inequalities $J_{2 n}(w) \leqslant \varepsilon_{n}, J_{2 n}\left(w_{n}\right) \leqslant \varepsilon_{n}$ $\left(\varepsilon_{n} \rightarrow 0\right)$. However, if $U+V$ is a linear subspace, since $\left(w-w_{n}\right) \in U+V$ it can be shown that $J_{2 n}\left(w-w_{n}\right) \leqslant \varepsilon_{n}$ the same way that it was for $J_{2 n}(w)$ or $J_{2 n}\left(w_{n}\right)$.

It is a very regrettable fact that Lemma 5 ii) and Theorem 3 respectively have an incorrect proof and no proof at all so that Theorem 4 need not to be true.

(*) Entrata in Redazione il 20 ottobre 1984.

26* - Annali di Matematica 